\title{
The relation between gastric acid secretion and body habitus, blood groups, smoking, and the subsequent development of dyspepsia and duodenal ulcer
}

\author{
B. H. NOVIS, ${ }^{1}$ I. N. MARKS, S. BANK, AND A. W. SLOAN \\ From the Gastrointestinal Clinic, Groote Schuur Hospital, and the Departments of Medicine and Physiology, \\ University of Cape Town, South Africa
}

SUMMARY One hundred and seventy-six students free of gastrointestinal disease were studied to establish normal acid secretion values for healthy male and female students by the augmented histamine test and to re-examine the relationship between gastric acid secretion and ABO blood groups, body weight, fat-free body mass, height, degree of ectomorphy and mesomorphy, the number of cigarettes smoked per day, and serum cholesterol. A prospective study was then carried out on gastric acid secretion and the subsequent development after 10 years of duodenal ulcers or dyspepsia.

Young, healthy medical students have a fairly high mean basal and maximal acid output. There was very little difference in the mean acid outputs of the various $\mathrm{ABO}$ blood groups. A significant correlation was shown between acid output and body weight and fat-free body mass, but not with the other measurements of body build. Basal acid output was also related to the number of cigarettes smoked per day. Three students who subsequently developed duodenal ulcers all had a preexistent high level of acid secretion. The acid output was, however, similar in the groups who developed significant or minor dyspepsia or who remained asymptomatic.

Gastric acid secretion varies with many physiological and pathological factors and the maximal acid output has been shown to be directly related to the parietal cell mass by Card and Marks (1960). There are still varying opinions about the relationship of gastric acid secretion and body habitus. Baron (1964) concluded that no significant association existed in normal males and ulcer patients between acid secretion and body build. Hume and Melrose (1967) showed a significant correlation with lean body mass. This was confirmed more recently by Desai, Zaveri, and Antia (1972) with body weight in controls.

Duodenal ulcers have been found to occur more frequently in persons with blood group $\mathrm{O}$ (Aird, Bentall, Mehigan, and Roberts, 1954) and cigarette smoking is often said to retard ulcer healing (Doll, Jones, and Pygott, 1958). The purpose of this paper is to re-examine the relationship between gastric acid

${ }^{1}$ Requests for reprints to be sent to: Dr B. H. Novis, Gastrointestinal Clinic, Groote Schuur Hospital, Cape Town, South Africa

Received for publication 8 November 1972. secretion and body habitus and to assess the correlation between blood groups, cholesterol, cigarette smoking, and gastric acid secretion.

As the subjects chosen for the study were mainly healthy medical students, this provided a unique opportunity to do a prospective study on gastric acid secretion and the subsequent development of duodenal ulcers and dyspeptic symptoms.

\section{Material}

One hundred and sixty medical students and 16 physiology students free of gastrointestinal disease (a few admitted to occasional postprandial heartburn) were studied in their second year at university. Eighteen of the students were females. Their average age was 20 years (age range 17-34). An augmented histamine test was performed in all 176 students in 1962. In 174 of these students, the ABO blood group was determined and in 169 the serum cholesterol estimated. The following anthropometric data were obtained in many of the students (number in 
parenthesis): (a) height (170); (b) weight (170); (c) percentage body fat (83) from which the fat-free body mass was derived, ie, body weight minus the percentage body fat; (d) the index of attenuation (height $/ 3 \sqrt{ }$ weight) as a measure of ectomorphy (74); (e) the chest breadth to height ratio as a measure of mesomorphy (74).

In addition, each student filled in a questionnaire about his cigarette smoking habits.

Ten years after the initial histamine tests, 160 of the students (the majority now medical practitioners, and whose addresses were therefore obtained from the medical directory) were sent questionnaires in which they were asked about dyspeptic symptoms, symptoms suggestive of a possible ulcer, or whether a duodenal ulcer had actually been diagnosed. One hundred and forty-two replies were obtained.

\section{Methods}

The augmented histamine tests were carried out as previously described (Marks, 1961; Marks, Bank, Louw, and Van Embden, 1962). The fasting student was intubated with a no. 14 Rüsch tube which was positioned under fluoroscopic control and fasting gastric contents were aspirated and discarded. Basal secretion was collected for one hour, by continuous wall suction at $5 \mathrm{~mm} \mathrm{Hg}$ and intermittent hand suction. An antihistamine was given intramuscularly 30 minutes after the commencement of the basal collection. At the end of the basal hour, histamine acid phosphate $(0.04 \mathrm{mg}$ per $\mathrm{kg}$ body weight) was given subcutaneously. Gastric contents were then collected in 15-minute samples for one hour. Aliquots of the basal hour and post-histamine hour collections were titrated with $0 \cdot 1 \mathrm{NaOH}$ using Töpfer reagent and phenolphthalein as indicators. The volumes and acid concentrations were measured and from these the total acid output of the basal samples (basal acid output, BAO) and of the posthistamine samples (maximal acid output, MAO) were calculated.

ABO blood grouping was performed by the blood transfusion laboratory and serum cholesterols by the modified Liebermann-Buchard method (Abell, Levy, Bernard, and Kendall, 1952).

Anthropometric data were obtained by the physiology laboratory. The percentage body fat was measured by the method of Sloan, Bert, and Blyth (1962) in which skin folds were measured at the following sites: (a) anterior abdominal wall halfway between the umbilicus and the top of the symphysis pubis; (b) the side of the thorax in the midaxillary line level with the xyphoid; and (c) the back of the arm in the midline half way between the acromium and olecranon processes with the shoulder adducted and elbow extended. All skin-fold measurements were done in duplicate. The percentage fat was calculated by the formula of Keys and Brožek (1953).

The index of attenuation (Hooton) was derived from the following formula: $\frac{\text { Height in } \mathrm{cm}}{\sqrt[3]{\text { weight in } \mathrm{g}}}$

The index is greater in the ectomorph than in the endomorph or mesomorph.

The height to transverse diameter ratio as a measure of mesomorphy was derived from the formula: $\frac{100 \times \text { chest breadth in } \mathrm{cm}}{\text { Height in } \mathrm{cm}}$

The ratio is higher in the mesomorph than in the ectomorph or endomorph.

In the questionnaire sent out 10 years after the initial testing the students (mostly now qualified medical men) were asked three questions which were then used to divide them into four groups according to their answers. (a) Have you developed a peptic ulcer and how was this diagnosed? (b) If you have not actually had an ulcer diagnosed have you had symptoms suggestive of a possible ulcer, namely, periodic epigastric pains related to meals and relieved by antacids or night pains? (c) Have you had any dyspeptic symptoms which are unlikely to be actual ulcer dyspepsia, ie, heartburn, epigastric pain, pain relieved by antacids, loss of appetite, chronic diarrhoea or constipation. The fourth group was those who were totally asymptomatic.

\section{Results}

In the 176 students tested the basal acid output (BAO) was $5.2 \pm 3.9 \mathrm{~m}$-equiv $/ \mathrm{hr}$ (mean \pm standard deviation) and the mean maximal acid output (MAO) was $26 \cdot 2 \pm 10 \cdot 2 \mathrm{~m}$-equiv/hr (Table I). In the 158 male students (average weight: $68.5 \mathrm{~kg}$ ) the mean BAO was $5.4 \pm 4.1 \mathrm{~m}$-equiv $/ \mathrm{hr}$ and the mean MAO was $26.8 \pm 10.2 \mathrm{~m}$-equiv $/ \mathrm{hr}$. Acid secretion was lower in the 18 females (average weight $=57.7 \mathrm{~kg}$ ) tested, the mean BAO was $3.0 \pm 2.0 \mathrm{~m}$-equiv $/ \mathrm{hr}$, and the mean MAO was $20.7 \pm 8.4 \mathrm{~m}$-equiv $/ \mathrm{hr}$. Histamine-fast achlorhydria occurred in two students. A BAO greater than $10 \mathrm{~m}$-equiv $/ \mathrm{hr}$ and an MAO greater than $40 \mathrm{~m}$-equiv/hr occurred in $10 \%$ of the male but none of the female students tested. The highest BAO in the group was 22.7 $\mathrm{m}$-equiv/hr and the highest MAO was $61.3 \mathrm{~m}$-equiv/ hr (Fig. 1).

The 83 students with blood group $\mathrm{O}$ had a BAO of $5.9 \pm 3.9 \mathrm{~m}$-equiv/hr (mean $\pm \mathrm{SD}$ ) and an MAO of $27.5 \pm 9.0 \mathrm{~m}$-equiv/hr (Table II). The mean acid output in the 58 students with blood group $\mathrm{A}$ 


\begin{tabular}{|c|c|c|c|c|c|}
\hline & Number & $B A O(\text { m-equiv/hour })^{1}$ & $M A O$ (m-equiv/hour) & Achlorhydria & $\begin{array}{l}B A O>10 \\
M A O>40\end{array}$ \\
\hline $\begin{array}{l}\text { Male students } \\
\text { Female students } \\
\text { All students }\end{array}$ & $\begin{array}{r}158 \\
18 \\
176\end{array}$ & $\begin{array}{l}5.4 \pm 4.1 \\
3.0 \pm 2.0 \\
5.2 \pm 3.9\end{array}$ & $\begin{array}{l}26 \cdot 8 \pm 10 \cdot 2 \\
20 \cdot 7 \pm 8 \cdot 4 \\
26 \cdot 2 \pm 10 \cdot 2\end{array}$ & $\begin{array}{l}1 \\
1 \\
2\end{array}$ & $\begin{array}{r}16 \\
0 \\
16\end{array}$ \\
\hline
\end{tabular}

Table I Acid secretory data in the students tested by the augmented histamine test

${ }^{1} \mathrm{BAO}=$ basal acid output (mean \pm standard deviation); $\mathrm{MAO}=$ maximal acid output (mean \pm standard deviation)

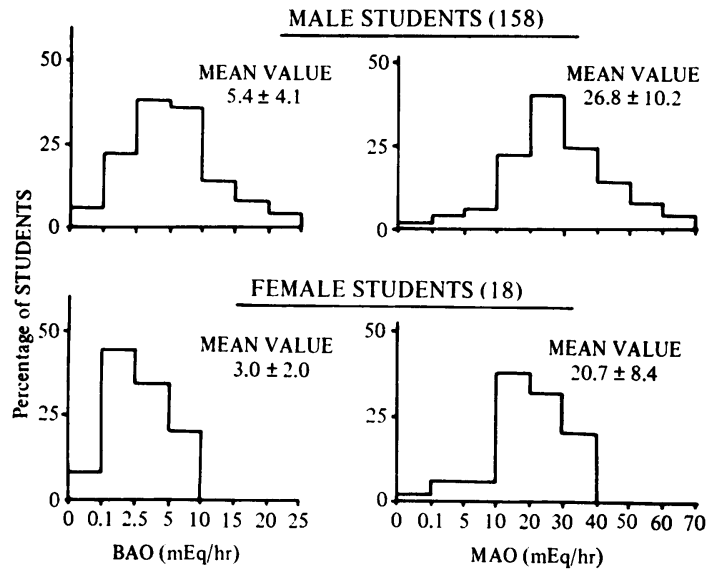

Fig. 1 Histogram showing basal and maximal acid output in the 158 male and 18 female students.

\begin{tabular}{lrll}
\hline Blood Group & No. & $\begin{array}{l}\text { BAO } \\
\text { (m-equiv/hour) }\end{array}$ & $\begin{array}{l}\text { MAO } \\
\text { (m-equiv/hour) }\end{array}$ \\
\hline O & 83 & $5.9 \pm 3.9$ & $27.5 \pm 9 \cdot 0$ \\
A & 58 & $4 \cdot 7 \pm 4 \cdot 1$ & $24.7 \pm 11 \cdot 1$ \\
B & 26 & $4 \cdot 1 \pm 3.9$ & $25 \cdot 5 \pm 13 \cdot 0$ \\
AB & 7 & $3.9 \pm 3.8$ & $26.0 \pm 12 \cdot 4$
\end{tabular}

Table II The mean basal and maximal acid outputs \pm standard deviations in the four $A B O$ blood groups ${ }^{1}$

'Differences not statistically significant was $\mathrm{BAO}=4 \cdot 7 \pm 4.1 \mathrm{~m}$-equiv $/ \mathrm{hr}$ and $\mathrm{MAO}=$ $24.7 \pm 11 \cdot 1 \mathrm{~m}$-equiv/ $\mathrm{hr}$. The 26 students with group B had a mean BAO of $4.1 \pm 3.9 \mathrm{~m}$-equiv/hr and an MAO of $25.5 \pm 13.0 \mathrm{~m}$-equiv $/ \mathrm{hr}$. The seven students with group $A B$ had a mean BAO of $3.9 \pm 3.8$ and an MAO of $26.0 \pm 12.4 \mathrm{~m}$-equiv/hr. There was no significant difference $(P>0 \cdot 15)$ between the acid output (basal and maximal) of any of the blood groups.

The basal and maximal acid outputs were correlated with body weight, fat-free body mass, height, the index of attenuation, the ratio of chest breadth to height, serum cholesterol, and with the number of cigarettes smoked per day. The two students with achlorhydria were excluded from these correlations. The results of the correlation coefficient ( $r$ ) and the $P$ value for each are shown in Table III and Figure 2.

Of the 142 who answered the questionnaire, only three persons, all males (average weight $65.9 \mathrm{~kg}$ ), had developed radiologically proven duodenal ulcers, all had high acid outputs BAO/MAO $=6 \cdot 2 / 29 \cdot 5$ m-equiv/hr, 22.7/47.2 m-equiv/hr, and $9 \cdot 4 / 35 \cdot 7$ m-equiv/hr (Figs. 3 and 4).

Twenty persons at some stage in the 10-year period between the test and answering the questionnaire had symptoms suggestive of a possible peptic ulcer but without an ulcer being definitely diagnosed. This group had a BAO of $4.5 \pm 3.5 \mathrm{~m}$-equiv/hr (mean \pm SD) and a mean MAO of $25.6 \pm 11 \cdot 2$ m-equiv/hr.

Forty-eight persons had minor dyspeptic symptoms

\begin{tabular}{|c|c|c|c|c|}
\hline & \multicolumn{2}{|l|}{$B A O$} & \multicolumn{2}{|l|}{$M A O$} \\
\hline & $\begin{array}{l}\text { Correlation } \\
\text { Coefficient } r\end{array}$ & $P$ Value & $\begin{array}{l}\text { Correlation } \\
\text { Coefficient } \boldsymbol{r}\end{array}$ & $P$ Value \\
\hline $\begin{array}{l}\text { Weight } \\
\text { Fat-free mass } \\
\text { Height } \\
\text { Smoking } \\
\text { Index of attenuation } \\
\text { Chest/height ratio } \\
\text { Serum cholesterol }\end{array}$ & $\begin{array}{r}0.1839 \\
0.2298 \\
0.1768 \\
0.2672 \\
-0.0525 \\
-0.0037 \\
0.0434\end{array}$ & $\begin{array}{l}<0.05 \\
<0.05 \\
>0.05 \\
<0.05 \\
>0.05 \\
>0.05 \\
>0.05\end{array}$ & $\begin{array}{r}0.4149 \\
0.3557 \\
0.1131 \\
0.1927 \\
-0.1078 \\
0.1115 \\
0.1449\end{array}$ & $\begin{array}{l}<0.001 \\
<0.01 \\
>0.05 \\
>0.05 \\
>0.05 \\
>0.05 \\
>0.05\end{array}$ \\
\hline
\end{tabular}

Table III The correlation coefficients $(r)$ and the $\mathrm{P}$ value for basal acid output and parameters of body build, smoking, and serum cholesterol 


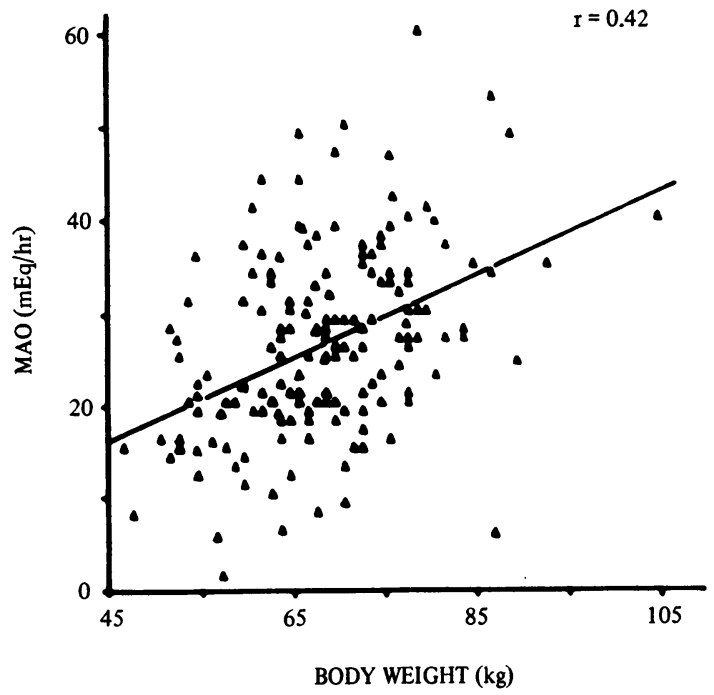

Fig. 2 Relationship between maximal acid output and body weight. $r=0.4149, y=0.4486 x-4.0188$ $(\mathrm{P}<0.001)$.

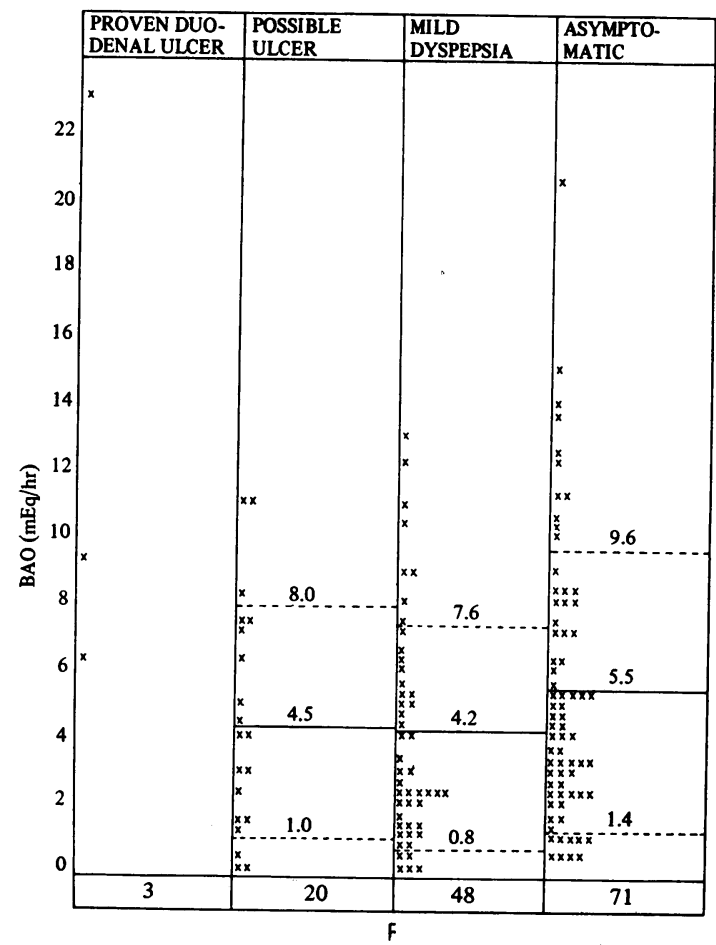

Fig. 3 Basal acid output in 142 students who returned the questionnaire with mean \pm standard deviation of four groups according to their answers. $X=$ Basal acid output. at some period in the 10 years after testing, often related to stress or dietary and alcoholic indiscretions. This group had similar acid outputs compared with the other two groups, ie, a mean BAO of $4 \cdot 2 \pm 3.4$ m-equiv/hr and a mean MAO of $24.8 \pm 11.7$ m-equiv/hr.

Seventy-one persons claimed never to have had any dyspeptic symptoms and this group had a mean BAO of $5 \cdot 5 \pm 4 \cdot 1 \mathrm{~m}$-equiv/hr and a mean MAO of $26.8 \pm 8.7 \mathrm{~m}$-equiv/hr.

The mean acid outputs were also calculated in all those who had had symptoms of heartburn, epigastric pain, and night pain. The mean BAO and MAO in these three symptom groups are shown in Table IV. The differences were not significant.

\begin{tabular}{llll}
\hline Symptom & No. & $\begin{array}{l}\text { BAO } \\
\text { (m-equiv/hour) }\end{array}$ & $\begin{array}{l}\text { MAO } \\
\text { (m-equiv/hour) }\end{array}$ \\
\hline Heartburn & 46 & $4.9 \pm 4.4$ & $25.8 \pm 9.5$ \\
Epigastric pain & 24 & $4.5 \pm 3.4$ & $25.7 \pm 9.4$ \\
Night pain & 13 & $4.9 \pm 3.5$ & $26.2 \pm 9.0$
\end{tabular}

Table IV The mean basal and maximal acid outputs \pm standard deviation of subsequent dyspeptic symptoms

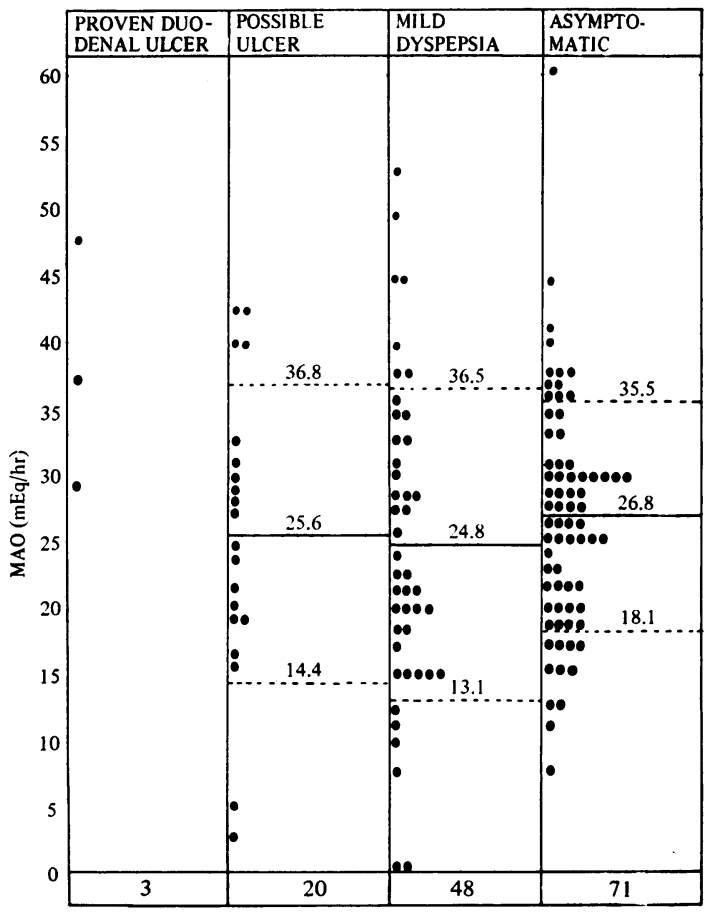

Fig. 4 Maximal acid output in 142 students who returned the questionnaire with mean \pm standard deviation of the four groups. - = Maximal acid output. 


\section{Discussion}

\section{BODY BUILD}

Previous studies correlating the maximal acid output and body build by measurements of height, weight, surface area, and lean body mass have produced conflicting reports. In normal adult males a significant correlation between maximal acid output and body weight was obtained by Marks (1961). Baron (1964) showed that 'in normal subjects there were correlations of possible significance' between peak acid output and height in men and between peak acid output and weight and surface area in women, but found all other correlations negative and therefore concluded that no definite significant association existed between gastric secretion and body build. Similar conclusions were reached by Vakil and Mulekar (1965) and by Goyal, Gupta, and Chuttani (1966) in normal male subjects. However, significant correlations have been found between maximum acid output and weight in infants and children (Ghai, Singh, Walia, and Gadekar, 1965; Kopel and Barbero, 1967). Hume and Melrose (1967) in a small series of eight normal subjects and 23 ulcer subjects found a significant correlation between maximal acid output and lean body mass in both the normal and duodenal ulcer subjects. The correlation between peak acid output and body weight (and lean body mass) was later confirmed by Baron (1969) in restudying a combination of data in two groups of normal subjects and patients with ulcers. Desai et al (1972) in India have also recently shown a significant correlation at the $5 \%$ level between body weight and MAO in 40 control males.

Card and Marks (1960) showed that the maximal acid output is directly related to the parietal cell mass and suggested that the lower acid output in women appeared to be a reflection of their smaller stature and thus of a smaller parietal cell mass. The finding in this study of a significant correlation between maximal acid output and body weight supports this suggestion. The correlation between body weight and MAO was highly significant $(r=0.4149 ; P<0.001)$ and was slightly better than the correlation between MAO and fat-free body mass $(r=0.3557 ; P<0.01)$ in this study. The difference between the two ' $r$ ' values was, however, not significant by Z-transformation $=0.5$.

We were unable to show any significant correlation between the acid output and height or between the acid output and the degree of ectomorphy as measured by the index of attenuation or the degree of mesomorphy as measured by the chest diameterheight ratio. No correlation was found between the acid output and serum cholesterol levels.

In this series of young healthy students the mean acid output (BAO/MAO) of $5 \cdot 2 / 26 \cdot 2$ was higher than in a group of 61 middle-aged controls with a mean acid output of $3 \cdot 2 / 19 \cdot 1$. Hospital patients free of gastrointestinal disease had a considerably lower mean level than either of the above two groups, confirming that young healthy persons have a greater acid production than their middle-aged counterparts and even higher than unwell hospital patients.

The acid secretion was considerably (but not statistically significant, $P>0.4$ ) lower in the 18 females tested than in the males which correlated well with their lower body weight.

\section{BLOOD GROUPS}

The study of acid secretion and blood groups provided no positive conclusions. Two of the students who had proven duodenal ulcers had blood group $\mathrm{A}$ and the other group $\mathrm{O}$. The 83 students with blood group $\mathrm{O}$ had a minimally higher acid output than the 58 students with group A, the 26 students with group $B$, and the seven students with group AB. However, these differences were not significant at the $5 \%$ level (Student's $t$ test). These findings suggest that although duodenal ulcer may be commoner in patients with blood group $\mathrm{O}$, the relationship of the level of acid output and the blood group is probably not the factor of aetiological importance. A previous study on blood groups and gastric acidity by Køster, Sindrup, and Seegle (1955) showed that conditions associated with the least production of acid have an increased frequency of blood group A, while conditions associated with the greatest production of acid have an increased frequency of blood group $\mathrm{O}$. Although the study encompassed a large number of patients and controls very few had acid secretory studies performed and the results were simply based on their conclusions on the range of acid secretion in duodenal ulcer, gastric ulcer, normal, and carcinoma of the stomach.

\section{SMOKING}

A particularly interesting finding was the significant correlation between basal acid output and the number of cigarettes smoked per day but not with the maximal acid output. This raises the possibility that cigarette smoking over a long period stimulates either the vagus or basal gastrin secretion, possibly through a nicotinic effect. Previous studies on the effect of smoking on gastric acid secretion have been inconclusive. Cooper and Knight (1956) found no difference in acid secretion between a group of duodenal ulcer patients who smoked and those who refrained during the study. Debas, Cohen, Holubitsky, and Harrison (1971) observed no significant overall change in acid secretion in 12 volunteers who smoked 
three cigarettes over a one-hour period of pentagastrin-stimulation test but some individuals did experience a significant secretory response. The finding in our study would tend to support the contention of Doll et al (1958) that cigarette smoking may retard ulcer healing.

\section{SUBSEQUENT DEVELOPMENT OF ULCER DYSPEPSIA}

The use of healthy medical students provided the unique opportunity to do a prospective study, after a 10-year period, during which they were under strain of examinations for about five years and thereafter from house jobs to registrarships or private practice, on the relationship between gastric acid secretion, tested at a time when none of them had any significant gastrointestinal symptoms, and the later development of duodenal ulceration or 'dyspepsia'. Of the 176 students tested, 16 were physiology students and only six of these could be traced. Four of the medical students did not proceed to qualify and they could not be traced and two had died in accidents. Questionnaires were therefore sent to 160 persons and of these 142 completed the questionnaire.

Of the three who had developed proven duodenal ulceration one had the highest basal acid output of the whole group, ie, $22.7 \mathrm{~m}$-equiv/hour, and all three had high basal and maximal acid outputs. Twenty persons had at some stage had symptoms suggestive of a possible ulcer. This group had a similar basal and maximal acid output to the 48 persons who had minor dyspeptic symptoms and, indeed, to the 71 persons who claimed never to have had dyspeptic symptoms.

In a similar follow-up study on 85 healthy men who had histamine test meals performed 15 years previously, Doll, Jones, and MacLagan (1949) found that the average volume of gastric juice secreted in the 10 who had developed symptoms suggestive of peptic ulcer (none proven) was significantly higher than that secreted by the rest. No difference was found in the maximum free acidity nor in the amount of free acid secreted per hour. Following up these same men 13 years later Baron (1962) found that seven had now developed proven duodenal ulcers and 15 had dyspepsia but found no significant difference in the acid secretory data of those with no dyspepsia and those with duodenal ulcers. These studies were unfortunately limited by the poor discrimination obtained using the old submaximal histamine test and no conclusion could be drawn on 'whether hypersecretion precedes or follows duodenal ulceration'.

This premorbid study, the first using an augmented histamine test, indicates that persons developing a duodenal ulcer are very likely to have a high acid secretion even before the ulcer has developed. This study, however, also shows that a high acid output frequently occurs in people with no predisposition to the development of duodenal ulcers or even minor dyspeptic symptoms, for some considerable period at least. But it should be borne in mind that the average age at the time of the follow-up survey was 30 years at which age very few duodenal ulcers would be expected to have developed. It is therefore hoped to repeat this study in this department in a further 10 and 20 years time.

We would like to thank Dr J. G. Burger, Medical Superintendent, for permission to publish. We would also like to thank Dr L. Krut for performing lipid studies and Dr M. Moshal for technical assistance. This study was supported by the Medical Research Council for South Africa.

\section{References}

Abell, L. L., Levy, B. B., Bernard, B. B., and Kendall, F. E. (1952). A simplified method for the estimation of total cholesterol in serum and demonstration of its specificity. J. biol. Chem., 195, 357-366.

Aird, I., Bentall, H. H., Mehigan, J. A., and Roberts, J. A. F. (1954) Blood groups in relation to peptic ulceration and carcinoma of colon, rectum, breast and bronchus. Brit. med. J., 2, 315-321.

Baron, J. H. (1962). Gastric secretion in relation to subsequent duodenal ulcer and familial history. Gut, 3, 158-161.

Baron, J. H. (1964). Peptic ulcer, gastric secretion and body build. Gut, 5, 83-85.

Baron, J. H. (1969). Lean body mass, gastric acid and peptic ulcer. Gut, 10, 637-642.

Card, W. I., and Marks, I. N. (1960). The relationship between the acid output of the stomach following 'maximal' histamine stimulation and the parietal cell mass. Clin. Sci., 19, 147-163.

Debas, H. T., Cohen, M. M., Holubitzky, I. B., and Harrison, R. C. (1971). Effect of cigarette smoking on human gastric secretory responses. Gut, 12, 93-96.

Desai, H. G., Zaveri, M. P., and Antia, F. P. (1972). Body-weight and maximal acid output. Postgrad. med. J., 48, 87-90.

Doll, R., Jones, F. A., and MacLagan, N. F. (1949). Gastric secretion and subsequent dyspepsia. Lancet, 2, 984-985.

Doll, R., Jones, F. A., and Pygott, F. (1958). Effect of smoking on the production and maintenance of gastric and duodenal ulcers. Lancet, 1, 657-662.

Ghai, O. P., Singh, M., Walia, B. N. S., and Gadekar, N. G. (1965). An assessment of gastric acid secretory response with 'maximal' augmented histamine stimulation in children with peptic ulcer. Arch. Dis. Child., 40, 77-79.

Goyal, R. K., Gupta, P. S., and Chuttani, H. K. (1966). Gastric acid secretion in Indians with particular reference to the ratio of basal to maximal acid output. Gut, 7, 619-623.

Hume, R., and Melrose, A. G. (1967). Relation between maximal acid output of stomach and lean body mass. Brit. med. J., 2 30-31.

Keys, A., and Brožek, J. (1953). Body fat in adult man. Physiol. Rev., 33, 245-325.

Kopel, F. B., and Barbero, G. J. (1967). Gastric acid secretion in infancy and childhood. Gastroenterology, 52, 1101.

Køster, K. H., Sindrup, E., and Seele, V. (1955). ABO blood groups and gastric acidity. Lancet, $2,52-55$.

Marks, I. N. (1961). The augmented histamine test. Gastroenterology, 41, 599-603.

Marks, I. N., Bank, S., Louw, J. H., and Van Embden, B. H. (1962). The augmented histamine test-an analysis of 672 consecutive tests. S. Afr. med. J., 36, 807-812.

Sloan, A. W., Burt, J. J., and Blyth, C. S. (1962). Estimation of body fat in young women. J. appl. Physiol., 17, 967-970.

Vakil, B. J., and Mulekar, A. M. (1965). Studies with the maximal histamine test. Gut, 6, 364-371. 